\title{
Назначение поэта: «исповедальность» лирики Блока vs. «стихи-предметы» Рильке*
}

\author{
MÁRIA GYÖNGYÖSI \\ ELTE BTK Orosz Nyelvi és Irodalmi Tanszék, H-1088 Budapest, Múzeum krt. 4/D. \\ Department of Russian Language and Literature, Faculty of Humanities, Eötvös Loránd University \\ E-mail: mgyongyosi12@gmail.com
}

(Received: 11 January 2018; accepted: 7 February 2018)

\begin{abstract}
The paper surveys the types of personal ('confessional') poetry and thing-poetry within the oeuvres of Blok and Rilke, respectively and compared to each other. Investigations have shown contact points in this underresearched domain, and also isolated a considerable number of poems in the cycle Verses about the Beautiful Lady, distinct from the atmosphere of mysticism and expectations, which contain a great amount of realia and impressionistic depictions. Furthermore, Rilke's quasi-objective poetry (in Neue Gedichte) cannot be termed as 'objective'.
\end{abstract}

Keywords: thing-poems, sonnet, Blok, Rilke, symbolism, impressionism

Понятие «исповедальность» в настоящей статье употребляется в том смысле, который ему придал Александр Блок в своих Письмах о поэзии: «Только то, что было исповедью писателя, только то создание, в котором он сжег себя дотла... может стать великим» (Блок 8: 35). Зародыш мысли об «исповедническом характере» лирики можно найти уже в ранних его поэтологических записях: «Стихи - это молитвы» (Блок 1963: 22). Блок формулирует и другое условие писательского бытия: «Первым и главным признаком того, что данный писатель не есть величина случайная и временная, - является чувство пути» (Блок 8: 102).

Стихи-предметы (русский эквивалент термина Dinggedicht) - тип стихотворения, воплощенный в творчестве Рильке в его Hовых стихотворениях и строящийся у Рильке на сложном взаимоотношении между субъектом и объектом, которое предстает не как статическое состояние, а как разворачивающийся процесс (RYAN 1972: 19, 24-25). Для сопоставления этих двух типов стихотворения весьма интересной оказывается та историко-литературная ситуация, когда в первом десятилетии XX века в немецкоязычной поэзии в двух книгах Новых стихотворений Рильке одной из своих вершин достигают стихи-предметы, - а в России крупнейший поэт времени Блок, знакомый со многими новыми явлениями европейской литературы, продолжает культивировать и признавать «исповеднический» тип поэзии, по крайней мере для русской публики (Блок 8: 36). Блок, подчеркивавший, что для него

\footnotetext{
* Предварительные варианты темы см. GYÖNGYÖSI 2013, ДьЁндьЁши 2016: 109-120.
} 
поэзия началась с Жуковского, а не с французских символистов (Блок 1963: 12), до конца своего творчества оставался верен эмоционально-музыкальному типу стихотворения, соответствующему определению поэзии А. В. Шлегелем: «Лирическое стихотворение является музыкальным выражением душевного волнения посредством языка». ${ }^{1}$ Это могло быть одной из причин, приведших к тому, что Мандельштам назвал Блока «просвещенным консерватором» и «человеком девятнадцатого века» (МАндельштАм 1990: 190, 189). В этой связи особую значимость приобретает «автобиографический миф» в творчестве Блока (МАГОМЕдовА 1997: 9).

Если присмотреться к статьям и письмам Блока, удивительно, насколько мало в них чисто поэтологических (и относящихся прямо к лирике) высказываний, если не считать рецензий. Широкий контекст (исторический, общественный, религиозный, иногда политический), в котором он подходил к отдельным темам, даже литературным, диктовался, видимо, и «взвихренной» эпохой, в которую он жил, и его личным представлением о долге поэтапублициста (см. резкую блоковскую критику нормативного тона в чисто литературной эссеистике Н. Гумилева). Блок ни на минуту не отвлекался от жгучих вопросов о судьбе России и деле поэта, от размышлений о классической русской литературе и современном ему литературном процессе, о статусе интеллигенции и обязанности художника (а это - «служение»; см. Блок 8: 131), о критике, театре и мн. др.

Нет возможности прослеживать все темы его статей, остановимся лишь на 4 ключевых текстах и развернутых в них концепциях. Блок называет лирика «Ангелем-Демоном», а лирику сравнивает с «водопадом» и «стихией» (О лирике, 1907) (Блок 7: 62-63). Услышав «звуки небес», художник-гений должен «сложи[ть] слова и записа[ть] их» (Памяти Врубеля, 1910) (Блок 8: 121). В статье-«завещании» О назначении поэта наблюдается два новых акцента. Во-первых, подчеркивается аполлоновское начало искусства: «Поэт сын гармонии». Во-вторых, созданную им гармонию поэт вносит в мир, чтобы, испытав ею людей, «добыть нечто более интересное, чем среднечеловеческое, из груды человеческого шлака» (Блок 1962b: 165). Согласно Блоку, поскольку «Россия - молодая страна, и культура ее - синтетическая», то «никаких чисто „литературных“ школ в России никогда не было» («Без божества, без вдохновенья». Цех акмеистов, 1921) (Блок 1962b: 175, 177). Однако он порицает акмеистов не только за их идеал «искусства для искусства», но и за то, что они «в своей поэзии... замалчивают самое главное, единственно ценное: душу» (Блок 1962b: 183).

В задачу данной статьи не входит прослеживание связей, которые способствовали (или потенциально могли способствовать) заочному знакомству Рильке и Блока, не будем заниматься также сопоставлением их творческого

${ }^{1}$ A. W. Schlegel: Vorlesungen über dramatische Kunst und Literatur (1809-1811). Цит. по: MÜLLER 1979: 17. Похожая мысль у Шиллера: поэзия музыкального типа выявляет «определенное состояние души» (цит. КОРЕЦКАЯ 1975: 223). 
пути и эволюции их поэтик. Эти аспекты темы были подробно разработаны К. Азадовским (см. АзАдовский 1991). ${ }^{2}$ В центре нашего внимания стоит не затронутый исследователем вопрос о типологическом сравнении исповедальной лирики Блока и стихов-предметов Рильке.

В цикле Стихи о Прекрасной Даме можно выделить четыре важных, взаимосвязанных тематических комплекса: 1) мистическое ожидание Прекрасной Дамы - к этой теме можно отнести большинство стихотворений; 2) утрата и воспоминание; 3 3) призвание поэта (представление о котором у Блока коренится в романтизме - см. Быстров 2012: 154), тема языка и стихов; $\left.{ }^{4} 4\right)$ путь и вечность. ${ }^{5}$ В 1900-1901 гг. в сознании Блока установился платоновско-соловьевский дуализм «мира идеальных сущностей» (в частности Вечной Женственности, объединяющей идеал немецких романтиков, соловьевскую Софию и черты Богоматери - ТАРАновский 2000: 319-320) и их воплощения - земного мира. Лексика ранних стихов отвлеченная (Быстров 2012: 154, например, «Нет меры нашему познанью» ${ }^{6}$ ), стилистика полна недосказанности и неопределенности («Неясный звук невнятного моленья, / Неведомый, бескрылый, страшный зов» ${ }^{7}$ ), также традиционных поэтизмов; настроение сновидческое, таинственное. В статье Александр Блок В. Я. Брюсов ретроспективно писал: «...в стихах о „Прекрасной Даме“ как бы совсем нет ничего реального» (Брюсов 2004: 223), а по словам Л. Гинзбург, в них «все развеществлено» (ГинзБург 1997: 252).

${ }^{2}$ Не только Блок не проявил особого интереса к поэзии Рильке (впрочем также современных немецкоязычных поэтов и писателей вообще), но и Рильке в основном остался чужд русскому символизму: «Wenn man bedenkt, daß R. zu einer Zeit nach Rußland reiste, als die russische Literatur den zweiten großen Höhepunkt ihrer Entwicklung erlebte..., dann erstaunt, wie wenig er von dieser äußerst lebendigen, vielfältigen Literaturszene wahrgenommen hat. Besonders auffallend ist die Ignoranz gegenüber dem russischen Symbolismus» (LEHMANN 2004: 103, см. также ДьЁндьЁши 2016: 65-67). Интересно отметить некоторые общие интересы и увлечения Рильке и Блока: это, в частности, Флобер, Стриндберг (RILKE 1986: 401) и Верхарн (LAUTERBACH 2004: 74-75); поэты занимали сходную позицию в отношении к цивилизации и истории (о Рильке cм. STORCK 2004: 24), а также заметны некоторые образные переклички в их поэзии, например, вегетативные метафоры лирического я: «Зеленею, таинственный клен» у Блока (Блок 1: 114); «Ich bin ein Baum vor meinem Hintergrunde...» (RILKE 1: 264); далее - мотив струны: «И напев заглушённый и юный / В затаённой затронет тиши / Усыплённые жизнию струны / Напряженной, как арфа, души...» у Блока (Блок 3: 134); «Ich bin eine Saite, / über rauschende breite / Resonanzen gespannt» (RILKE 1: 401).

${ }^{3} \mathrm{~K}$ этому тематическому разряду относятся стихотворения Я понял смысл твоих стремлений...; В день холодный, в день осенний... и мн. др.

${ }^{4} \mathrm{~K}$ этой группе принадлежат стихи Всё бытие и сущее согласно...; Они звучат, они ликуют...; И я, неверный, тосковал ...; Не жди последнего ответа... и т. д.

${ }_{5}^{5}$ В качестве стихотворений, где эта тема эксплицитно не сплетена с темой Прекрасной Дамы, можно назвать, в частности, Я вышел. Медленно сходили...; Стою на иарственном пу$m u . .$. К особой группе, собственно, следовало бы причислить стихи, в которых лирическим субъектом является Прекрасная Дама, например, Хранила я среди младых созвучий...; Медленно в двери церковные...

${ }^{6}$ Мы все простим - и не нарушим... (Блок 1: 96).

${ }^{7}$ Я помню час глухой, бессонной ночи... (Блок 1: 65). 
Однако в небольшой доле цикла все-таки встречаются реалии и автономные описания, не подчиненные мистическим темам (хотя символическая насыщенность концовки или всего стихотворения и в этих случаях нередки). Если миниатюра Белой ночью месяц красный... отличается красочностью, то стихотворение Сгущзался мрак цуерковного порога ... поражает пейзажными деталями и образом путника, который «задумчив и смущен» (Блок 1: 90). Стихотворение Брожу в стенах монастыря... пронизано лейтмотивом белизны и бледности, символика которых, однако, резко расходится. В стихотворении На ржавых петлях открываю ставни... необходимо выделить импрессионистичность первой строфы. В стихотворении Золотистою долиной... элегическое настроение передается образами эфемерности («тающий» крик журавлей, «прозрачные волокна» паутины - Блок 1: 118), а в стихотворении Свобода смотрит в синеву... - визуальными (красочными), акустическими и тактильными деталями. Самый интересный пример с точки зрения данной статьи - стихотворение Там - в улице стоял какой-то дом... (Блок 1: 105).

Уже первая строфа неожиданно богата реалиями и конкретными («прозаическими») деталями: дом, лестница, крутая, дверь, стекло, свет и тьма. Дальше - дверной навес, прикреплен болтом; вывеска «Цветьл», лампа желтая, окно и штора, карниз, пенье, музыка и танцыь, двор. Лирический сюжет динамизируется целым рядом лексем, схватывающих изменения в описываемой картине (вылегал, мелькала, вдруг), описание сенситивно, импрессионистично ${ }^{8}$ (открывалась дверь, звеня стеклом; в сумерках белел дверной навес; дрожал свет; лампа чуть светила). Ритм изменений, а также осознания чувственных импрессий несколько раз обозначается пунктуацией: тире в стихах 4, 8 и 15 выражает паузу в лирической речи. Хотя это стихотворение явно нельзя причислить к жанру стихов-предметов, в нем обнаруживается новый облик ранней лирики Блока: вторжение реального, динамичного предметного мира в тишину и мистицизм Стихов о Прекрасной Даме, и стихотворение отличается от цикла и тем, что «душа» прячется: я грамматически не появляется, а единственное, что можно сказать о лирическом герое, заключается в том, что он стоит против описываемого здания (а временами во дворе и смотрит на лестницу). Личность лирического я ощущается только в выборе деталей, а также в метафорах и сравнениях, в которых первичные зрительные и акустические импрессии преподнесены читателю (Cвет вblбегал; тьма бродила; словно лоб наморщенный, карниз / Гримасу придавал cmене - и взоры). (Из биографии Блока и его писем к Любови Дмитриевне Менделеевой мы знаем, что он ждал ее у входа в дом, где проводились драматические курсы Читау - Блок 1: 530.)

К тому же 1902 г. приурочивают самый ранний образец стихов-предметов Рильке, стихотворение Der Panther. Im Jardin des Plantes, Paris (Пантера), вошедшее впоследствии в его сборник 1907 г. Neue Gedichte (RILKE 1: 505).

${ }^{8}$ Ср. с характеристикой поэзии Блока у Пастернака (ПАСтеРнАК 1991: 311). Об импрессионистических началах поэзии Блока см. также КОРЕЦКАЯ 1975: 215. 
Как известно, в творчестве Рильке огромное влияние на возникновение стихов-предметов оказало искусство Родена, с которым Рильке познакомился в Париже в 1902 г., а позже - живопись Сезанна. До того - как об этом свидетельствует его доклад Современная лирика (Moderne Lyrik, Прага, 1898) Рильке считал задачей лирического поэта откровение чувств (Gefühlsoffenbarungen), личные признания («ganz persönliche Geständnisse»), исповедь ощущений (Empfindungsbeichten) (RILKE 5: 365-368). Он отмечает «холодную, чуть ли не бедную ясность» стихов Стефана Георге в его «чисто формальных вероисповеданияХ» (RILKE 5: 378).

$\mathrm{B}$ отличие от своего раннего представления о лирике как о непосредственной исповеди чувств, в одном из Писем к молодому поэту Рильке утверждает:

Каждое впечатление, каждый зародыш чувства должен созреть до конца в себе самом, во тьме, в невысказанности, в подсознании, в той области, которая для нашего разума непостижима, и нужно смиренно и терпеливо дождаться часа, когда тебя осенит новая ясность: только это и значит - жить, как должен художник: все равно в творчестве или в понимании (РильКЕ 1977: 334).

В этом же письме к Ф. К. Каппусу фигурирует сравнение «поэт» - «дерево», ${ }^{9}$ родственное мысли Блока. ${ }^{10}$

С опять изменившейся позиции пишет Рильке о назначении художника Кларе Вестхофф, анализируя искусство Сезанна. С точки зрения постулата чистой вещности особенно интересно письмо от 13 октября 1907 г.. ${ }^{11}$

Раз от разу все яснее замечаешь, как было необходимо стать выше даже любви; естественно, что художник любит каждую из тех вещей, которые он создает; но если это подчеркивать, то вещь становится хуже: мы начинаем судить о ней вместо того, чтобы просто о ней сказать. [...] Художник пишет: я люблю эту вещь, вместо того чтобы написать: вот она. [...] Так она [т. е. любовь] вся без остатка расходуется в самом акте создания. [...] он [т. е. Сезанн] сумел не выдать ничем свою любовь к каждому яблоку, чтобы в яблоке, написанном на холсте, дать ей жизнь навсегда (РильКЕ 2013).

Описание пантеры в Зоологическом саду Парижа ${ }^{12}$ проходит в нескольких перспективах. Во-первых, как смотрит на зверя и его клетку посетитель, ощущая ее узость и следя за монотонным движением зверя за решеткой. Вовторых, с внешней точки зрения говорящего в стихотворении поэта, который

9 «...расти, как дерево, которое не торопит своих соков и встречает вешние бури без волнений, без страха, что за ними вслед не наступит лето» (РильКЕ 1977: 334).

10 «исатель - растение многолетнее. Как у ириса или у лилии росту стеблей и листьев сопутствует периодическое развитие корневых клубней, - так душа писателя расширяется и развивается периодами, а творения его - только внешние результаты подземного роста души» (Блок 8: 102).

11 Это одно из его почти ежедневных писем Кларе, возникших под впечатлениями ретроспективной выставки работ Сезанна в парижском Осеннем салоне.

${ }^{12}$ На самом деле Рильке вдохновила небольшая скульптура Родена (POR 1997: 73). 
всматривается в зрелище более внимательно, замечая как усталость пантеры, так и гибкие (выражаемые многократным повтором дифтонга $e i$ ) и сильные (передаваемые повтором $t$ ) ее шаги (в переводе Вяч. Куприянова: «походку»см. Рильке 2006: 110), «занавес значка», поднимающийся временами, а также «напряженное спокойствие» всех частей тела. И, наконец, говорящий является знатоком процессов, невидимых для посторонних наблюдателей. Он проникает чувством во внутренний мир пантеры, в определенном смысле отождествляя себя с ней и вмещаясь в ее перспективу: за тысячей прутьев нет мира; ей кажется, как будто...; «случайный образ пробежит по членам / и в сердие растворится на века». Этого единственного слова «сердце» достаточно, как мне кажется, чтобы стихотворение выходило за пределы «безличного, эпически-объективного описания», о котором говорит словарное определение стихов-предметов (WILPERT 2001: 176). Констатацией того, что внешний образ достигает сердца и замирает в нем, поэт осмысляет всем доступное зрелище в экзистенциальном ракурсе, придавая ему в заостренной концовке стихотворения трагическую безысходность, ведь сердце - средоточие не только чувств, но и жизни. Причем, использование в последней строфе своеобразной и синтаксически не мотивированной пунктуации, ${ }^{13}$ которая имеет ретардирующую функцию (тире перед точкой и тире перед und), можно интерпретировать как обозначение отрезков времени 1) на сюжетном уровне: это время, пока увиденная картина внешней реальности доходит до сознания пантеры, 2) на уровне лирической речи: это паузы, обусловленные размышлениями лирического я, пытающегося расшифровать значение взгляда и движения зверя. Этот третий, высший уровень наблюдения зрелища поэтом можно назвать осмысляюще-экзистенциальным. Сюда же относится сравнение (типичная стилистическая фигура Рильке в этот период творчества ${ }^{14}$ ): поступь пантеры уподобляется танцу сил вокруг центра, в котором - «оглушенная» «большая воля». Воля пантеры, однако, уничтожена, сила не имеет никакой цели и возможности применения. Таким образом, якобы объективное изображение пантеры превращается в субъективное ${ }^{15}$ вчувствование во внутренний мир и судьбу пленного зверя.

Три уровня описания в проведенном анализе близки распространенной в литературе о Рильке тезе о том, что Новые стихотворения обладают своеобразной структурой (воплощаемой часто в сонете), которая выражает стадии динамического процесса: показ оппозиции (пантера и мир), появление начала, связующего полюсы и посредствующего между ними (как пантера воспринимает клетку), и внезапный поворот (Umschlag): «в замирании мгно-

${ }^{13}$ О специфике знаков препинания и о парентезах у Рильке см. STAHL 2011.

${ }^{14} \mathrm{~B}$ своей знаменитой речи Проблемы лирики Готфрид Бенн, усматривая в КАК-конструкциях «убывание языкового напряжения, слабость творческой трансформации», называет сравнения Рильке исключением («Rilke war ein großer WIE-Dichter») (BENN 1959: 504) и приводит в качестве примера строфу из стихотворения Голубая гортензия.

${ }^{15}$ Райан пишет о нескольких составляющих субъективности в Новых стихотворениях, в частности, о сравнениях, которые, создавая внезапные смысловые связи, открывают новые перспективы (RYAN 1972: 26). 
венном / расширится отверстие зрачка», превращение (Verwandlung, может и отсутствовать, как и в этом случае) (RYAN 1972: 24-25).

«Поворот» и «превращение» характерны для описания вещи также в стихотворении Blaue Hortensie, написанном в середине июля 1906 г. (Neue Gedichte - RILKE 1: 519). Если в стихотворении Пантера не было личного местоимения, указывающего на лирического субъекта, то в стихотворении Голубая гортензия (перевод А. Биска) появляется слово таn (общее подлежащее), заменяющее местоимение $я$, а лирический субъект, грамматически исчезающий из текста, очевидно соглашается с тем, что думают и чувствуют люди (см. ниже). Далее, интересно, что в тексте фигурируют слова, характеризующие не цветок, а мир человека и, в частности, - лирического субъекта и его мир (в первом терцете совсем нет намека на гортензию - MÜLLER 2004: 299): слезы («слезная влага»), старинная голубая бумага, лексема «трогательно», ${ }^{16}$ соотносящаяся с качеством голубого цвета. Постепенно растет эмоциональность метафор и сравнений (MÜLLER 1971: 160) вплоть до развернутого сравнения, в котором «застиранность» голубизны цветка уподобляется цвету детского фартука, который никто больше не носит. Рильке восклицает (в оригинале нет восклицательного знака): «Как этой жизни краткость ощутима!» (wie fühlt man eines kleinen Lebens Kürze). Этим он окончательно дает читателю почувствовать, что лирическим сюжетом является не просто точное описание всех нюансов цвета голубой гортензии и его изменения, а нечто другое, большее, - вопросы человеческой жизни, времени, тленности бытия. Деталь «детский фартук», который никто больше не носит, наводит на мысль о смерти ребенка. В последнем терцете, в кульминации стихотворения, как будто происходит внезапная перемена: голубизна одного цветка становится яркой, интенсивной и получает человеческий признак: она «радуется». Напряжение, пронизывавшее лирический сюжет, достигло кульминации и разрешилось в новом качестве цвета, но в то же время важна и эмоциональная сторона опыта: грусть и трагические ассоциации сменяются умилением и радостью. В этом стихотворении перелом, происходящий в начале второго терцета, совпадает с характерной для сонета пуантой (MÜLLER 1971: 144). ${ }^{17}$ Немотивированность перелома внешними обстоятельствами (например, солнечным светом) допускает вывод, что изменились собственно восприятие и эмоции лирического субъекта, опосредованно отражающиеся на новой, «умилительной голубизне» цветка. Поэт элиминирует дистанцию между я и цветком посредством гипаллаги, приписывая гортензии собственную «радость» (HERRES 2010: 177-178).

Проведенный анализ двух стихотворений свидетельствует, что стихипредметы Рильке не лишены эмоциональности, «души», присутствующих в них в скрытом виде, т. е. они имеют признаки, первостепенные в художественной системе Блока. Описание Рильке вещей не остается в рамках ни

\footnotetext{
${ }^{16}$ В переводе А. Биска «синь» не имеет атрибута.

${ }^{17}$ Пуанта в сонетах Рильке расположена обычно в первом или втором терцетах (RYAN 1972: 60).
} 
объективности, ни впечатлительности. Вещи имеют для него эстетическую значимость при наличии феномена «превращения», происходящего в них (MÜLLER 1971: 207), а сравнения и метафоры вносят в текст стихотворений «образы второго порядка» (ECKEL 2010: 138, т. е. то, что стоит за визуальностью самого предмета) и, за их счет, опыт, приобретаемый или активизируемый человеком в процессе столкновения с вещами. В этом «оформленном и эстетически трансформированном переживании вещи [Ding-Erlebnis] обращение к действительности и искусство символистского внушения убедительно связаны друг с другом» (ENGEL 2004: 179).

А почему Блок не обращался к жанру стихов-предметов? Думается, возможные причины этого уводят далеко от обстоятельств взаимоотношений русской и западноевропейской поэзии начала XX века. Поэзия Блока была сильно укоренена в русской традиции, а в произведениях тех поэтов XIX в., которые были особенно важны для Блока, этот жанр не играл особой роли. ${ }^{18}$ Некоторое значение могло иметь также то свойство поэзии Блока, что она писалась и оформлялась Блоком при компоновке собрания сочинений как цельный «роман в стихах». Этот тип творчества, культивировавшийся русскими символистами, был обусловлен «их мифопоэтическими представлениями о творческом процессе как создании единого текста и единой книги (лирический ,„роман-миф“)» (ЙовАнович 2004: 327), а «вторжение» в него чужого типа стихотворения, пожалуй, мешало бы органичности целого. Кроме этого, в биографии Блока не было такого непосредственного, определяющей важности, соприкосновения с изобразительным искусством, имевшее место у Рильке (художница жена, жизнь рядом с Роденом, воздействие Сезанна). Итак, Блок остался «самой большой лирической темой Блока» (Тынянов 1977: 118), точнее, эмоции лирического я определяют каждое стихотворение его лирический сюжет, его краски и реалии, которые одновременно символичны (ТАРАнОВскиЙ 2000: 319); речь лирического героя (иногда героини) часто имеет адресата в рамках стихотворения. ${ }^{19}$ Пространство сюжетов обычно открыто (пейзаж, ведута) - кто мог бы себе представить Блока без горизонта («Весь горизонт в огне»), закатов («Желтый зимний закат за окном», «Фиолетовый запад гнетет, Как пожатье десницы свинцовой»), апокалиптических, космических картин («И все безумней вихрь планет Еще века, века!», в этом же стихотворении: «Все небо скроет гнусный грех»), без «ветра», «вьюги», «полей» и «дороги»? Описание какого-либо конкретного предмета не воспринималось Блоком как творческая задача.

Симптоматично также различие: пристрастие Рильке к сонету и редкость этого жанра у Блока. Сонет, частая форма Hoвых стихотворений, ${ }^{20}$ макси-

${ }^{18}$ Правда, у Пушкина есть такие стихи-предметы, как Цветок или Царскосельская статуя, а у Лермонтова - Могила бойца или Портрет (Взгляни на этот лик: искусством он...), но они сильно отличаются от немецких образцов этого жанра в XIX веке.

19 Этот голос может быть «заклинающим, гипнотизирующим» (ТАРАновский 2000: 336).

${ }^{20}$ Четверть сборника написана классическим сонетом, а вместе с различными вариантами и видоизменениями сонет в сборнике доминирует (см. RYAN 1972: 57-58). 
мально соответствовал для Рильке развертыванию сущности данного объекта, ибо в сонете сукцессивной эволюции стихов, полустроф, строф, двойных строф противодействует рифменная схема с ее обратными движениями: «abba abba cde cde» (форма, культивировавшаяся А. В. Шлегелем) или: «abba bccb ded fef» (например, Blaue Hortensie Рильке). Сонет - «разум форм, игра форм разума» (Hugo Friedrich, цит. по SCHLÜTTER 1979: 8) - явно чужд глубоко эмоциональной лирике Блока.

Стихи-предметы были и у Рильке переходным явлением его творчества, способствовавшим преодолению натурализма и декадентства, характерных для ранних произведений (ENGEL 2004: 176-179). Его стихотворение Wendung (1914) (RILKE 2: 83-84) (Перемена, перевод Куприянова - РилькЕ 2006: 204), всеобще рассматриваемое как художественный документ поэтологического поворота, рефлектирует кризис поэтики стихов-предметов («Anschauen») и необходимость обращения к «Herz-Werk», «деянию сердца» (ENGEL 2004: 180): «Denn des Anschauns, siehe, ist eine Grenze. / Und die geschaute Welt / will in der Liebe gedeihn. // Werk des Gesichts ist getan, / tue nun Herz-Werk / an den Bildern in dir»».

Своей апелляцией к «сердцу» мастер стихов-предметов в конечном счете приближается к эстетике Блока.

\section{Литература}

АЗАдовСКий 1991 = АзАдовский К. М. Райнер Мария Рильке и Александр Блок. Предварительные заметки. Русская литература 1991/2: 144-156.

Блок = Блок А. А. Полное собрание сочинений и писем в 20 томах. Москва, 1997-.

Блок 1962а = Блок А. Собрание сочинений в 8 томах. Т. 5. Москва-Ленинград, 1962.

Блок $1962 \mathrm{~b}=$ Блок А. Собрание сочинений в 8 mомах. Т. 6. Москва-Ленинград, 1962.

Блок 1963 = Блок А. Собрание сочинений в 8 томах. Т. 7. Москва-Ленинград, 1963.

Брюсов 2004 = Брюсов В. Я. Александр Блок. В кн.: Александр Блок: pro et contra. Личность и творчество Александра Блока в критике и мемуарах современников. Санкт-Петербург, 2004. 221-233.

БЫСтРОв 2012 = БыстРОв В. Н. Между утопией и трагедией. Идея Преображения мира у русских символистов. Москва, 2012.

ГинзБУРГ 1997 = ГинзБУРг Л. О лирике. Москва, 1997.

ДьЁндьёши 2016 = ДьЁндьёши Мария: Стих - ичикл - поэтика. Блок, Рильке, Пастернак. (Русская культура в Европе / Russian Culture in Europe 12.) Frankfurt am Main, 2016.

ЙовАнОвич 2004 = ЙовАнович Миливое: Миф о «вечном возвращении» в разделе «Родина» Александра Блока. В кн.: ЙовАнович Миливое: Избранные труды по поэтике русской литературы. Белград, 2004. 323-361.

КОРЕЦКАЯ 1975 = КОРЕЦКАЯ И. В. ИМПрессИОНИЗм в ПОэЗИИ И эстеТИКе сиМВоЛИЗМа. В кн.: Литературно-эстетические конщепции России конщу XIX-начала XX века. Москва, 1975. 207-251.

МАГОМЕДОВА 1997 = МАГОМЕДОВА Д. М. Автобиографический миф в творчестве Александра Блока. Москва, 1997.

МАНДЕЛЬШТАМ $1990=$ МАНДЕЛЬШТАМ Осип: Сочинения в 2 томах. Т. 2. Москва, 1990. 
ПАСТЕРНАК 1991 = ПАСТЕРНАК Б. Л. Собрание сочинений в 5 томах. Т. 4. Повести. Статьи. Очерки. Москва, 1991.

Рильке 1977 = Рильке Райнер Мария: Письма к молодому поэту. В кн.: РАЙНЕР Мария Рильке: Новые стихотворения. Новых стихотворений вторая часть. Москва, 1977. 326-365.

РиЛьКЕ 2006 = РиЛькЕ Райнер Мария: Избранныле стихотворения. Москва, 2006.

РильКЕ 2013 = РильКЕ Райнер Мария: Письма о Сезанне. http://www.librapress.ru/2013/ 07/Rajner-Marija-Rilke-Pisma-o-Sezanne.html.

ТАРАНОВСКИЙ 2000 = ТАРАНОВСКИЙ К. Ф. НекоТорЫе черты символики Блока. В кН.: ТАРАНОВСКИЙ К. Ф. О поэзии и поэтике. Москва, 2000. 319-329.

Тынянов 1977 = Тынянов Ю. Блок. В кн.: Тынянов Ю. Поэтика. История литературы. Кино. Москва, 1977. 118-123.

BENN 1959 = BENN Gottfried: Gesammelte Werke in 4 Bänden. Band 1. Essays, Reden, Vorträge. Wiesbaden, 1959.

ECKEL 2010 = ECKEL Winfried: Bild und Figur in der Lyrik des Symbolismus. Beobachtungen zu Baudelaire, Mallarmé und Rilke. In: SimON Ralf, Herres Nina, LöRINCZ Csongor (Hg.): Das lyrische Bild. München, 2010. 113-152.

ENGEL 2004 = ENGEL Manfred: Vier Werkphasen. In: ENGEL Manfred (Hg.): Rilke-Handbuch: Leben - Werk - Wirkung. Stuttgart-Weimar, 2004. 175-182.

GYÖNGYÖSI 2013 = GYÖNGYÖSI Mária: В чем назначение поэта? «Исповедальность» лирики Блока vs. «стихи-предметы» Рильке. В кн.: Revitalizace hodnot. Umění a literatura. Kolektivní monografie. Brno, 2013. 147-155.

Herres 2010 = Herres Nina: Kein Ort, an dem der Schwan geschont wird. Epiphanie und Entzug einer Allegorie (Horaz, Rilke, Mallarmé). In: Simon Ralf, Herres Nina, LÖRINCZ Csongor (Hg.): Das lyrische Bild. München, 2010. 155-179.

LAUTERBACH 2004 = LAUTERBACH Dorothea: Frankreich. In: ENGEL 2004: 60-88.

LEHMANN 2004 = LeHMANN Jürgen: Rußland. In: ENGEL 2004: 98-112.

MÜLLER 1971 = MÜLLER Wolfgang: Rainer Maria Rilkes „Neue Gedichte“. Vielfältigkeit eines Gedichttypus. Meisenheim am Glan, 1971.

MÜLLER 1979 = MÜLLER Wolfgang: Das lyrische Ich. Erscheinungsformen gattungseigentümlicher Autor-Subjektivität in der englischen Lyrik. Heidelberg, 1979.

MÜLLER 2004 = MülLER Wolfgang: Neue Gedichte / Der Neuen Gedichte anderer Teil. In: ENGEL 2004: 296-318.

POR $1997=$ Por Peter: „Bruchstellen seines immensen Stoffes“": zur Poetik von Rilkes „Neue Gedichte". Budapest, 1997.

RILKE 1986 = RILKE Rainer Maria, THURN UND TAXIS Marie von: Briefwechsel. Frankfurt am Main, 1986.

RILKE 1987 = RILKE Rainer Maria: Sämtliche Werke. Bd. 1-6. Frankfurt am Main, 1987.

RYAN 1972 = RYAN Judith: Umschlag und Verwandlung. Poetische Struktur und Dichtungstheorie in R. M. Rilkes Lyrik der mittleren Periode (1907-1914). München, 1972.

SCHLÜTTER 1979 = SCHLÜTTER Hans-Jürgen: Sonett. Stuttgart, 1979.

STAHL 2011 = STAHL August: ,(unterbrich mich nicht: du irrst)“. Zur Interpretation einiger

Parenthesen in Rilkes Lyrik. In: F. BALOGH András, VARga Péter (Hg.): „das Leben in der Poesie“. Festschrift für Magdolna Orosz zum 60. Geburtstag. Budapest, 2011. 171-184.

STORCK 2004 = STORCK Joachim W. Leben und Persönlichkeit. In: ENGEL 2004: 1-25.

WILPERT 2001 = WILPERT Gero von: Sachwörterbuch der Literatur. Stuttgart, 2001. 